\title{
NOTA SOBRE A OCORRÊNCIA NATURAL DE ALBIZIA INUNDATA (MART.) BARNEBY \& GRIMES NO RIO GRANDE DO SUL ${ }^{1}$
}

\author{
JOSÉ NEWTON CARDOSO MARCHIORI ${ }^{2}$ FABIANO DA SILVA ALVES ${ }^{3}$
}

\section{RESUMO}

É comprovada a ocorrência natural de Albizia inundata (Mart.) Barneby \& Grimes no município de Barra do Quaraí, Rio Grande do Sul, Brasil.

Palavras-chave: Albizia inundata, Fabaceae, Leguminosae Mimosoideae, Mimosaceae, Rio Grande do Sul.

\section{ABSTRACT}

[Note about the natural occurrence of Albizia inundata (Mart.) Barneby \& Grimes in Rio Grande do Sul state, Brazil].

The natural occurrence of Albizia inundata (Mart.) Barneby \& Grimes is presently confirmed to the municipality of Barra do Quaraí, Rio Grande do Sul state, Brazil.

Key words: Albizia inundata, Fabaceae, Leguminosae Mimosoideae, Mimosaceae, Rio Grande do Sul state.

\section{INTRODUÇÃO}

Conhecida pelos nomes populares de timbóbranco, bigueiro, biguazeiro, canafístula e muquém (Lorenzi, 1998), Albizia inundata (Mart.) Barneby \& Grimes apresenta ampla distribuição geográfica na América do Sul, encontrando-se naturalmente no Brasil, Paraguai, Argentina e Uruguai (Izaguirre \& Beyhaut, 2003).

De acordo com Lorenzi (1998), a espécie é nativa na Região Amazônica, vale do São Francisco e Pantanal Matogrossense, em matas ciliares e várzeas inundáveis.

Para a província argentina de Entre Rios, Burkart (1987) indica sua ocorrência tanto em ilhas como à margem dos rios Paraná, Uruguai e principais afluentes, até o Delta Superior e Médio, na embocadura do Prata.

Na República Oriental do Uruguai, a espécie habita "zonas úmidas próximo à água", em matas ciliares do rio Uruguai (Brussa \& Grela, 2007).

1 Recebido em 09-12-2011 e aceito para publicação em 05-01-2012.

2 Engenheiro Florestal, Dr. Professor Titular do Departamento de Ciências Florestais, UFSM. Bolsista de Produtividade em Pesquisa ( $\mathrm{CNPq}$ - Brasil).

3 Biólogo, MSc. Professor da Universidade da Região da Campanha (URCAMP - Alegrete). Doutorando do Programa de Pós-Graduação em Eng. Florestal, UFSM.
Para Santa Catarina, embora "ainda não observada", Burkart (1979) aventa a possibilidade de sua ocorrência no sudoeste do Estado ${ }^{4}$, municípios de Chapecó, Palmitos, Mondaí e Itapiranga.

No estado do Rio Grande do Sul, a literatura apresenta informações contraditórias, justificando a realização do presente artigo.

A respeito de Arthrosamanea polyantha (Spreng.) Burkart), binômio atualmente reduzido à sinonímia de Albizia inundata, Rambo (1966) atribui sua ocorrência em toda a Floresta Pluvial da metade norte do Estado, com base em coletas procedentes de Santa Maria, São Leopoldo, Feliz, Montenegro, Nonoai e Farroupilha, entre outros municípios. O exame deste material, entretanto, levou Sobral et al. (2006) a reconhecer que as exsicatas correspondem a Albizia edwalii, uma espécie distinta.

No "Projeto Madeira do Rio Grande do Sul", Reitz et al. (1983) incluíram Cathormion polyanthum (Spreng.) Burkart, binômio igualmente reduzido à sinonímia de Albizia inundata, entre as espécies nativas no Estado, mais preci-

\footnotetext{
4 Burkart (1979) refere-se a Cathormion polyanthum (Spreng.) Burkart, binômio atualmente reduzido à sinonímia de Albizia inundata.
} 
samente na "região fitogeográfica" do Alto Uruguai. Pelos motivos anteriormente expostos, pode-se afirmar que esta citação também carece de fundamento na região apontada.

Em obra sobre Leguminosas arbóreas, Marchiori (1997) incluiu Cathormion polyanthum entre as árvores nativas do Rio Grande do Sul. As fotografias que ilustram o texto descritivo mostram folhas alternas com 2 a 4 pares de pinas, folíolos opostos, lanceolado-subfalcados, e legumes achatados, lineares ${ }^{5}$. Cumpre informar que o material utilizado nas ilustrações foi coletado na mata ciliar do rio Quaraí, arredores da cidade de Barra do Quaraí. Na segunda edição da mesma obra (Marchiori, 2007), a espécie figura como Albizia inundata, binômio atualmente válido.

Em conhecida obra de referência, Sobral et al. (2006) excluíram Albizia inundata da flora nativa, com base na inexistência, em herbários, de coletas provenientes do Rio Grande do Sul. Resta assinalar que a espécie não é citada, igualmente, na Flora Digital do Rio Grande do Sul (www.ufrgs.br/floradigital).

O presente trabalho tem o objetivo de esclarecer definitivamente o tema, comprovando a ocorrência natural de Albizia inundata no extremo sudoeste do Rio Grande do Sul, mais precisamente no Pontal do Quaraí (município de Barra do Quaraí), região em que a espécie ocorre, com abundância, nas matas ciliares dos rios Uruguai e Quaraí.

\section{DESCRIÇÃO BOTÂNICA}

Árvore inerme, de até $8 \mathrm{~m}$ de altura e $30 \mathrm{~cm}$ de DAP, com copa rala e casca espessa, rugosa, de cor clara. Folhas compostas, bipinadas (1-4 pares de pinas), de $9-18 \mathrm{~cm}$ de comprimento, provida de glândula peciolar séssil, arredondada, e múcron setiforme na extremidade da raque. Folíolos opostos, glabros, linear-falcados (8-20 x 4-8 mm), de base assimétrica, em 6-17 pares por pina. Flores branco-esverdeadas, em

5 MARCHIORI, J.N.C. Dendrologia das Angiospermas: Leguminosas. Santa Maria: Ed. UFSM, 1997. p. 69. racemos de capítulos ou panículas axilares e apicais. Cálice campanulado $(1 \mathrm{~mm}), 5$-dentado, com cílios na margem dos dentes. Corola tubuloso-campanulada, glabra, com cinco pétalas de $3 \mathrm{~mm}$ de comprimento. Estames de 5-7 $\mathrm{mm}$ de comprimento, em número de 30-40 por flor, soldados em curto tubo na corola. Fruto linear (até $20 \mathrm{~cm}$ de comprimento e $1,5 \mathrm{~cm}$ de largura), achatado, subcoriáceo, glabro, reticulado, marginado, bivalvo, com endocarpo que se desprende em articulações quadradas (cerca de 1,2 cm), monospérmicas.

Sinonímia botânica: Acacia inundata Martius, em Spix \& Martius Reise Bras. 1:555, 1823; Holotypus: Brasil: "in virgultis ad f. S. Francisco prope Salgado ... Aug. (1818)". Acacia polyantha Sprengel, Syst. Veg. 5:3, 1828. Arthrosamanea polyantha (Sprengel) Burkart, Darwiniana 9(1): 66, 1949. Cathormion polyanthum (Sprengel) Burkart, Darwiniana 13 (2-4): 447, 1964. Albizia polyantha (Sprengel f.) G.P. Lewis, Leg. Bahia: 164, 1987.

Etimologia: o nome genérico (Albizia) presta homenagem a Filippo degl'Albizzi, nobre florentino do século XVIII. O nome específico (inundata) foi criado por Martius e alude ao ambiente característico da espécie: áreas inundáveis.

Dados fenológicos: floração, em dezembro; frutos maduros de fevereiro a abril.

Material examinado: BRASIL: Rio Grande do Sul, Barra do Quaraí, à beira do rio Quaraí, $10 \mathrm{~m}$ a leste da ponte; flores branco-esverdeadas; Marchiori \& Alves, n. 1013, 03-12-2011 (HDCF). Barra do Quaraí; mata ciliar do rio Uruguai, próximo à foz do rio Quaraí; frutos jovens; Marchiori \& Alves, $\mathrm{n}^{\circ}$ 1014, 03-12-2011 (HDCF).

\section{COMENTÁRIOS}

Vistos à distância, os indivíduos adultos de Albizia inundata assemelham-se a timbaúvas de 


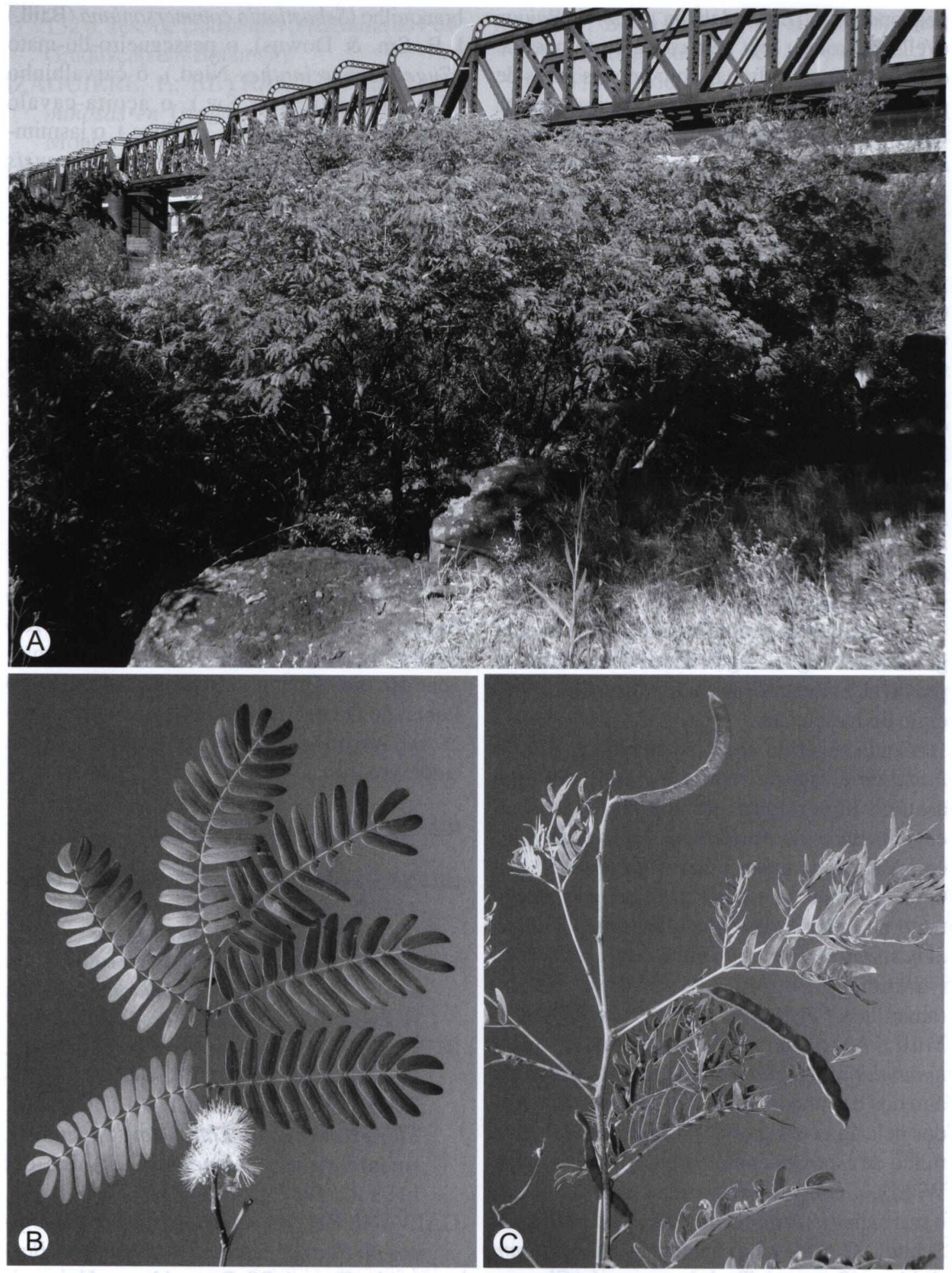

FIGURA 1 - Albizia inundata em Barra do Quaraí, Rio Grande do Sul. A - Indivíduos jovens, à margem do rio Quaraí, com a ponte ferroviária ao fundo. B - Ramo com folha e flores. C-Ramo com folhas e frutos jovens. 
pequeno porte (Enterolobium contortisiliquum (Vell.) Morong), seja pela casca do tronco, de cor clara, ou pelas folhas com poucos pares de pinas. A confusão não resiste, todavia, a exame mais atento: Albizia inundata apresenta frutos achatados (vs. contorcidos em espiral em Enterolobium contortisiliquum), além de detalhes relativos à forma e dimensão dos folíolos, bem como da estrutura floral.

A respeito de sua ocorrência no Rio Grande do Sul, pode-se afirmar que Albizia inundata é espécie nativa no Estado e que, apesar de sua distribuição restrita ao extremo sudoeste, chega a ser abundante em locais próximos à água dos rios Quaraí e Uruguai, na região do Pontal, bem como na mata ciliar adjacente. Cabe notar que, embora nativa na mata ciliar do rio Uruguai, na área do Parque Estadual do Espinilho, a espécie não foi incluída por Galvani (2003) na lista da "vegetação arbórea/arbustiva" da referida unidade de conservação.

A distribuição geográfica da espécie ao longo do rio Uruguai segue desconhecida, sendo provável, entretanto, a sua ocorrência no município de Uruguaiana.

Como sugerido no nome científico, Albizia inundata é espécie reófila, motivo pelo qual assume importância em trabalhos de Bioengenharia e merece estudo, com vistas à recomposição de matas ciliares no oeste do Rio Grande do Sul. A espécie pode ser encontrada tanto na linha d'água, onde cresce ao lado de Sebastiania schottiana (Müll. Arg.) Müll. Arg. (sarandi), Terminalia australis Cambess. (amarilho), Phyllanthus sellowianus (Klotzsch) Müll. Arg. (sarandi-vermelho) e Salix humboldtiana Willd. (salso-crioulo), como no alto dos barrancos, em locais somente alcançados pela água das grandes enchentes, ambiente típico de espécies como o ingazeiro (Inga vera Willd.), a corticeira (Erythrina cristagalli L.), o marmeleiro (Ruprechtia salicifolia (Cham. \& Schltdl.) C.A.Mey.), a canafístula (Peltophorum dubium (Spreng.) Taub.), o aguaí (Chrysophyllum marginatum (Hook. \& Arn.) Radlk.), o branquilho (Sebastiania commersoniana (Baill.) L.B. Sm. \& Downs), o pessegueiro-do-mato (Eugenia myrcianthes Nied.), o carvalhinho (Casearia silvestris $\mathrm{Sw}$.), o açoita-cavalo (Luehea divaricata Mart. ex Zucc.), o jasmimcatavento (Tabernaemontana catharinensis DC.), o espinilho (Vachellia caven (Molina) Seigler \& Ebinger), a unha-de-gato (Senegalia bonariensis (Gillies ex Hook. et Arn.) Seigler \& Ebinger) e o juquiri (Mimosa uraguensis Hook. \& Arn.).

Além de sua importância na fixação do solo em matas ciliares, Albizia inundata fornece madeira com densidade de 0,5 a $0,6 \mathrm{~g} / \mathrm{cm}^{3}$, de acordo com Tortorelli (1956); fácil de ser trabalhada e de boa qualidade, a madeira é indicada para decoração de interiores (chapas, compensados) e pasta mecânica.

\section{CONCLUSÕES}

O timbó-branco (Albizia inundata (Martius) Barneby \& Grimes) é espécie nativa no Rio Grande do Sul, ocorrendo naturalmente à margem dos rios Quaraí e Uruguai, na região do Pontal do Quaraí. Embora rara no Estado, a espécie é importante para Bioengenharia, por seu caráter reófilo.

\section{REFERÊNCIAS BIBLIOGRÁFICAS}

BRUSSA SANTANDER, C.A.; GRELA GONZÁLEZ, I.A. Flora arbórea del Uruguay. Montevideo: COFUSA, 2007. 542 p.

BURKART, A. Leguminosas Mimosoideas. In: REITZ, P.R. Flora Ilustrada Catarinense. Itajaí: Herbário Barbosa Rodrigues, 1979. 299 p.

BURKART, A. Leguminosae (= Fabaceae), Leguminosas. In: BURKART, A.; BURKART, N.S. T. de; BACIGALUPO, N.M. Flora Ilustrada de Entre Ríos (Argentina). Buenos Aires: Colección Científica del I.N.T.A., 1987. p. 442-738.

GALVANI, F.R. Vegetação e aspectos ecológicos do Parque Estadual do Espinilho, Barra do Quaraí, RS. Porto Alegre: Universidade Federal do Rio Grande do Sul, 2003. 
132 p. Tese de Doutorado (Programa de PósGraduação em Botânica).

IZAGUIRRE, P.; BEYHAUT, R. Las Leguminosas en Uruguay y regiones vecinas. Montevideo: Hemisferio Sur, 2003. 301 p.

LORENZI, H. Árvores brasileiras. Manual de identificação e cultivo de plantas arbóreas do Brasil. Nova Odessa: Instituto Plantarum, 1998. v. 2. 352 p.

MARCHIORI, J.N.C. Dendrologia das Angiospermas: Leguminosas. Santa Maria: Ed. UFSM, 1997. 200 p.

MARCHIORI, J.N.C. Dendrologia das Angiospermas: Leguminosas. Santa Maria: Ed. da UFSM, 2007. 2. ed. 199 p.
RAMBO, B. Leguminosae Riograndenses. Pesquisas, Botânica, São Leopoldo, n. 23, p. 1-166, 1966.

REITZ, R.; KLEIN, R. M.; REIS, A. Projeto Madeira do Rio Grande do Sul. Sellowia, Itajaí, n. 34-35, p. 1-525, 1983.

TORTORELLI, L. A. Maderas y bosques argentinos. Buenos Aires: ACME, 1956. $910 \mathrm{p}$.

SOBRAL, M.; JARENKOW, J.A.; BRACK, P.; IRGANG, B.; LAROCCA, J.; RODRIGUES, R.S. Flora arbórea $e$ arborescente do Rio Grande do Sul, Brasil. São Carlos: RiMA : Novo Ambiente, 2006. $350 \mathrm{p}$. 